\title{
Molecular Characterization of FRAXB and Comparative Common Fragile Site Instability in Cancer Cells
}

\author{
Martin F. Arlt, ${ }^{1,2}$ Diane E. Miller, ${ }^{1,2}$ David G. Beer, ${ }^{3}$ and Thomas W. Glover ${ }^{1,2 *}$ \\ 'Department of Human Genetics, University of Michigan, Ann Arbor, Michigan \\ ${ }^{2}$ Department of Pediatrics, University of Michigan, Ann Arbor, Michigan \\ ${ }^{3}$ Department of Surgery, University of Michigan, Ann Arbor, Michigan
}

\begin{abstract}
The common fragile site, FRA3B, has been shown to be a site of frequent homozygous deletions in some cancers, resulting in loss of expression of the associated FHIT gene. It has been proposed that FHIT is a tumor suppressor gene that is inactivated as a result of the instability of FRA3B in tumorigenesis. More recently, deletions at other common fragile sites, FRA7G and FRA I6D, have been identified in a small number of cancer cell lines. Here, we have mapped and molecularly characterized the frequently observed common fragile site FRAXB, located at Xp22.3. Like other common fragile sites, it spans a large genomic region of approximately $500 \mathrm{~kb}$. Three known genes, including the microsomal steroid sulfatase locus (STS), map within the fragile site region. We examined FRAXB and four other fragile sites (FRA3B, FRA7G, FRA7H, FRA I6D), and several associated genes, for deletions and aberrant transcripts in a panel of cancer cell lines and primary tumors. Deletions within FRAXB were seen in 4/27 (14.8\%) of the primary tumors and cell lines examined. Three of the 21 (14.3\%) cell lines examined were characterized by loss of expression of one or more FRAXB-associated genes. Moreover, all of the fragile sites examined were characterized by genomic deletions within the fragile site regions in one or more tumors or cell lines, including FRAXB, which is not associated with any known tumor suppressor genes or activity. Our results further support the hypothesis that common fragile sites and their associated genes are, in general, unstable in some cancer cells. (c) 2002 Wiley-Liss, Inc.
\end{abstract}

\section{INTRODUCTION}

Chromosome fragile sites are loci that are "hot spots" for gaps and breaks on metaphase chromosomes when DNA synthesis is perturbed (reviewed in Glover, 1998). There are two classes of fragile sites, rare and common. Common fragile sites are expressed when cells are grown under conditions that inhibit DNA synthesis, such as folate deficiency or with aphidicolin, a specific inhibitor of DNA polymerases. They are seen in all individuals and represent a basic component of chromosome structure that is poorly understood. At least 80 common fragile sites exist, with at least one found on most human chromosomes.

Common fragile sites have been proposed to play a mechanistic role in chromosome translocations and other rearrangements in cancer cells in vivo, based on their behavior in vitro and their colocalization with chromosome breakpoints in vivo. In vitro, they have been shown to display characteristics of unstable and highly recombinogenic DNA, consistent with the hypothesis that fragile site gaps can lead to DNA double-strand breaks. After induction, these sites show increased sister-chromatid exchange on metaphase chromosomes and a high rate of deletions and translocations in somatic cell hybrid systems (reviewed in
Glover, 1998). In addition, it has been shown that breaks at fragile sites can trigger and set boundaries to gene amplification events in CHO cells (Coquelle et al., 1997).

Most information about the biological behavior of common fragile sites in vivo comes from the study of FRA3B, the most frequently seen fragile site on human metaphase chromosomes. It maps to a region of $3 \mathrm{p}$ known to be associated with deletions in a number of solid tumors (Glover et al., 1988; Hibi et al., 1992; Negrini et al., 1996) and spans the $\mathrm{t}(3 ; 8)$ breakpoint segregating in a family with hereditary renal cell carcinoma (Glover et al., 1988; Huebner et al., 1997). FRA3B maps to the same region as the FHIT gene (Ohta et al., 1996; Wilke et al., 1996; Huebner et al., 1997). The FHIT gene spans an estimated $900-1,000 \mathrm{~kb}$ of 3 p14.2. In contrast to its large genomic size, it encodes only a $1.1 \mathrm{~kb}$ transcript, the product of which is a hy-

\footnotetext{
Supported by: National Cancer Institute; Grant number: CA43222 (T.W.G.); the University of Michigan Comprehensive Cancer Center Pardee Fellowship (M.F.A.).

*Correspondence to: Thomas W. Glover, Ph.D., Department of Human Genetics, Box 0618, 4909 Buhl, University of Michigan, Ann Arbor, MI 48109-0618. E-mail: glover@umich.edu

Received 19 June 2001; Accepted 10 July 2001
} 
drolase involved in the cleavage of diadenosine triphosphates (Barnes et al., 1996). FRA3B maps in a region extending at least from FHIT intron 4 through part of the very large intron 5 , a distance of about $500 \mathrm{~kb}$ (Ohta et al., 1996).

The FHIT gene has been shown to be frequently deleted and to produce aberrant transcripts in a large number of tumor types (Negrini et al., 1996; Ohta et al., 1996; Sozzi et al., 1996; Druck et al., 1997; Michael et al., 1997). The FHIT protein was shown to be absent or reduced in cell lines harboring homozygous or hemizygous deletions (Druck et al., 1997). The deletions frequently span hundreds of kilobases and largely occur within FRA3B. In addition, at least four translocations with breakpoints in $F H I T /$ FRA3B have been reported (Ohta et al., 1996; Geurts et al., 1997; Fang et al., 2001). These findings are consistent with the hypothesis that FRA3B is unstable in some cancer cells and is mechanistically involved in the chromosome rearrangements. Based largely on the occurrence of frequent homozygous deletions, it was suggested that FHIT is a frequently inactivated tumor suppressor gene (Ohta et al., 1996). Whereas subsequent studies have left some doubt about the role of FHIT as a tumor suppressor gene (Otterson et al., 1998; Wu et al., 2000), recent functional studies have provided support for this view ( $\mathrm{Si}$ prashvili et al., 1997; Fong et al., 2000; Dumon et al., 2001).

A number of possibilities exist to account for the frequent deletions of the FHIT gene in tumors. First, the frequent FHIT deletions may be independent of FRA3B and are selected for during tumorigenesis. Second, the deletions may be caused by instability at FRA3B and, again, selected for due to the tumor suppressor function of FHIT. Third, the deletions may be caused by fragile site instability in certain tumor cells and are maintained without selection. The latter two possibilities invoke a mechanism of fragile site instability in certain cancer cells. If this is true, it would suggest that additional common fragile sites are also unstable in cancer. Limited data exist that directly address this question. Homozygous deletions have been observed in a small number of tumors at other fragile sites, including FRA7G in ovarian cancer and FRA16D in gastric adenocarcinoma and multiple myeloma, suggesting that common fragile sites are generally unstable and may lead to gene inactivation in cancer cells (Huang et al., 1999; Mangelsdorf et al., 2000). It is unclear whether these deletions represent generalized fragile site instability in cancer or simply a selective event that coincidentally includes fragile site loci.

Examining tumors for deletions and gene inactivation at other fragile sites is one way to provide insight into the mechanisms of fragile site instability and the role of FHIT as a tumor suppressor gene. In this article, we define the location, boundaries, and known genes associated with FRAXB, a frequently observed common fragile site that has not been associated with any known tumor suppressor gene locus. We examined the stability of FRAXB, its associated genes, and additional common fragile sites FRA7G, FRA7H, and FRA16D in a panel of cancer cell lines. Our results support the hypothesis that fragile sites, in general, are sites of frequent deletion in some cancer cells.

\section{MATERIALS AND METHODS}

\section{FISH}

Fluorescence in situ hybridization (FISH) was performed on metaphase cells from peripheral blood lymphocytes treated with $0.3 \mu \mathrm{M}$ aphidicolin to induce common fragile sites. As previously described (Dagenais et al., 1999), metaphase chromosome slides were denatured and then hybridized overnight with biotin-14-dATP-labeled probes. A BioNick Translation Kit (Gibco BRL, Gaithersburg, MD) was used to label probes from yeast artificial chromosome (YAC), bacterial artificial chromosome (BAC), and cosmid clones. Prior to hybridization, probes were denatured for $8 \mathrm{~min}$ at $70^{\circ} \mathrm{C}$ and preannealed for $30-60 \mathrm{~min}$ at $37^{\circ} \mathrm{C}$ with human Cot1 DNA (Gibco BRL). FISH signals were visualized by incubation with two layers of fluorescein isothiocyanate (FITC)-conjugated avidin-DCS (Vector Laboratories, Burlingame, CA) and fluorescein-conjugated anti-avidin IgG. Chromosomes were counterstained with 4',6-diamidino2-phenylindole (DAPI, Vector Laboratories). FISH results were analyzed with a Zeiss Axioscop epifluorescence microscope.

\section{Cell Lines and Tissue Specimens}

Esophageal adenocarcinoma tissue samples were obtained from patients undergoing surgical resection at the University of Michigan hospital. Consent was received from all patients, and the project was approved by the Institutional Review Board (Medicine). All patient identifiers were removed. Tumor specimens were frozen in liquid nitrogen and stored at $-70^{\circ} \mathrm{C}$. Primary tumor samples analyzed were M60, P16, F93, S45, D01, and L86. A panel of 21 cancer cell lines was also used in these 
experiments. These cell lines were derived from breast (HCC1937, SUM149, SUM159, SUM44, SUM102, SUM185, SUM190, SUM225, SUM229, SUM1315M02), cervical (HeLa, SiHa, CASKI, and CC-19), colon (HT-29, SW-480, LS180), gastric (KATOIII), and esophageal (BIC-1, FLO-1, SEG-1) carcinomas.

\section{DNA/RNA Extractions}

DNA was isolated from fresh tissue by standard proteinase $\mathrm{K}$ digestion and phenol extraction as previously described (Sambrook et al., 1989). Cell line DNA was isolated from confluent T75 flasks using the QIAamp Tissue Kit (Qiagen, Valencia, CA). Cell line total RNA was extracted from subconfluent T75 flasks using Trizol according to the manufacturer's instructions (Gibco BRL).

\section{Reverse-Transcription Polymerase Chain Reaction (RT-PCR)}

Five micrograms of total RNA was reverse transcribed in a total volume of $20 \mu \mathrm{l}$ using an oligo-(dT) primer and the Superscript II Reverse Transcriptase (Gibco BRL) according to the manufacturer's instructions. Four microliters of the RT reaction was used for one round of PCR amplification consisting of 30 cycles at $94^{\circ} \mathrm{C}$ for $1 \mathrm{~min}$, annealing temperature for 1 $\mathrm{min}$, and $72^{\circ} \mathrm{C}$ for $3 \mathrm{~min}$. The primers used to amplify FHIT transcripts were an exon 1 specific primer, 6159E (5'-CATCGTGGAAGCTTTGAAGCTCA$3^{\prime}$ ), and an exon 10 specific primer, 8243I (5'-CATGCTGATTCAGTTCGTCTTGG-3'). An annealing temperature of $56^{\circ} \mathrm{C}$ was used. The primers used to amplify the ATP7A transcript were an exon 3 specific primer, 64C (5'-GTCAGGAGCTTGTGAAGATCA-3'), and an exon 20 specific primer, $75 \mathrm{C}$ (5'CCCACATTAGCCATTGCCAGA-3'). An annealing temperature of $60^{\circ} \mathrm{C}$ was used. The STS transcript was amplified at an annealing temperature of $63^{\circ} \mathrm{C}$ using an exon 2 specific primer, 5691I (5'TTTCTGTGGGAAGCGGAGAG-3'), and an exon 10 specific primer, 3875I (5'-TGCTGAGGGGTGAGTTAAGG-3'). GS1 was amplified at an annealing temperature of $58^{\circ} \mathrm{C}$ using an exon 1 specific primer, 2707J (5'-CTCATCTTTGACATGGACGG-3'), and an exon 4 specific primer, 2706J (5'CAGACATATATTCAGGCGATCAAG-3'). TLR5a was amplified using an annealing temperature of $55^{\circ} \mathrm{C}$ with an exon 1 specific primer, 2705J (5'CTCGCGGAGAGCGTAGC-3'), and an exon 7 specific primer, 2704J (5'-CAATTTAAGGGTACATCAACAAGG-3'). With the exception of the FHIT RT-PCR reactions, all reactions were carried out using the Expand Long Template PCR System
(Roche, Indianapolis, IN). FHIT was amplified using standard Taq polymerase (Gibco BRL).

PCR products were analyzed on $1 \%$ agarose gels and visualized by staining with ethidium bromide. The products in the gel were then transferred to nylon membranes and hybridized with ${ }^{32} \mathrm{P}$-labeled cDNA probes specific to each reaction. Probes were labeled using the Random Primers Labeling Kit (Gibco BRL). Membranes were exposed to BioMax MS film (Eastman Kodak, Rochester, NY).

\section{Genomic PCR}

Genomic DNA was used as template for PCR with 25 markers from several common fragile sites. Markers from FRA3B were D3S2977, D3S4103, D3S1481, and FHIT exon 5 (forward 5'-TCATTTGGCTGGTTAGGCTC-3'; reverse 5'-AATGGCATCCTCTCTGCAAC-3'). Markers from FRA7G were D7S486, 7G2, and 7G14 (Huang et al., 1999). Markers from FRA7H were WI-16323 and D7S649. Markers from FRAXB were DXS6701, DXS1130, DXS1133, DXS1407, STS exon 2 (forward 5' -TTTCTGTGGGAAGCCGAGAG-3'; reverse 5'-GGTTTGGAGGGTTTTGAACG-3'), and STS exon 10 (forward 5'-CCAACACGCCTGAGAGTGGC-3'; reverse 5'-TGCTGAGGGGTGAGTTAAGG-3'). Control markers were D3S3577, D3S4483, D7S500, DXS8079, KAL intron 13 (forward 5'-GACCCAAGTCCACGTACTTC-3'; reverse 5'-TATCAAGCTCTCCCATTGTG-3'), and ATP7A exon 4 (forward 5'-TTCATCTTATCTCAGTAGAGG-3'; reverse 5'-TACTACCAACGGCTCATTCGT-3').

Markers were amplified with Taq DNA polymerase (Gibco BRL) in reactions containing $1.5 \mathrm{mM}$ $\mathrm{MgCl}_{2}, 0.2 \mathrm{mM}$ dNTPs, $0.1 \mu \mathrm{M}$ each primer, and $100 \mathrm{ng}$ of template DNA. When a marker failed to amplify in a sample in two consecutive PCR reactions, multiplex PCR was performed using the marker in question and a proven control marker. Reaction conditions were essentially the same as above, but we used $1.4 \mathrm{mM}$ dNTPs and $4 \mathrm{mM}$ $\mathrm{MgCl}_{2}$. PCR products were analyzed on $1 \%$ agarose gels and visualized by staining with ethidium bromide.

\section{RESULTS}

\section{Mapping FRAXB}

To determine precisely the location and boundaries of FRAXB, we performed FISH with ordered YAC clones from Xp22. One YAC, 933D4, was found to cross the fragile site on metaphase chromosomes from peripheral-blood lymphocytes treated with aphidicolin. These results indicate 
TABLE I. Identification of Cosmid, BAC, and YAC Clones at FRAXB

\begin{tabular}{|c|c|c|c|c|}
\hline Clone & Distal $^{\mathrm{a}}$ & $\begin{array}{c}\text { FISH } \\
\text { signal } \\
\text { crossing }^{b}\end{array}$ & Proximal $^{c}$ & $\begin{array}{l}\text { Position } \\
\text { relative to } \\
\text { FRAXB }\end{array}$ \\
\hline 3GI & 15 & 0 & 0 & Distal \\
\hline 19C7 & 7 & 0 & 0 & Distal \\
\hline 87BII & 12 & 0 & 0 & Distal \\
\hline 74A4 & 8 & 5 & I & Crossing \\
\hline YAC933D4 & 13 & 6 & 4 & Crossing \\
\hline YAC29CII & 4 & 2 & 4 & Crossing \\
\hline 37D9 & 5 & 6 & 2 & Crossing \\
\hline YAC29GI & 4 & 3 & 4 & Crossing \\
\hline BACI46LI & 9 & 3 & 5 & Crossing \\
\hline BAC388MI5 & 0 & 0 & 15 & Proximal \\
\hline BAC542P7 & 0 & I & 16 & Proximal \\
\hline \multicolumn{5}{|c|}{$\begin{array}{l}\text { aNumber of metaphase cells in which FISH signal was located distal to } \\
\text { the fragile-site break. } \\
\text { bNumber of metaphase cells in which FISH signal was divided across the } \\
\text { fragile-site break. } \\
\text { 'Number of metaphase cells in which FISH signal was located proximal } \\
\text { to the fragile-site break. }\end{array}$} \\
\hline
\end{tabular}

that FRAXB colocalizes with this clone. However, on some metaphase chromosomes, 933D4 hybridized either proximal or distal to the fragile site break, indicating that FRAXB extends beyond the boundaries of this YAC clone.

To determine the size and boundaries of FRAXB more accurately, we performed additional FISH experiments with a panel of YAC, BAC, and cosmid clones that map distal or proximal to YAC 933D4. We quantitated the number of times each clone hybridized proximal to, crossing, or distal to the fragile-site break. These data are summarized in Table 1. Three cosmid clones, 3G1, 19G7, and 87B11, were found to map exclusively distal to FRAXB, whereas an overlapping cosmid, 74A4, frequently crossed the break in addition to mapping distal to it. These data indicate that the distal boundary of FRAXB is near DXS1130, a marker shared by $87 \mathrm{~B} 11$ and 74A4 (Fig. 1A).

In addition to YAC 933D4 and cosmid 74A4, several clones were found to cross FRAXB. These clones include cosmid 37D9, YACs 29C11 and 29G1, and BAC 146L1. These clones represent the core of FRAXB and span from DXS1130 proximally past DXS1131.

Two overlapping BAC clones, 388M15 and $542 \mathrm{P} 7$, hybridized proximal to the fragile site on metaphase chromosomes. These clones contain DXS237 and DXS1132, respectively, and represent the proximal boundary of FRAXB. Based on these data the proximal boundary is positioned between DXS1133 and DXS237. Like FRA3B, FRAXB is a
A.
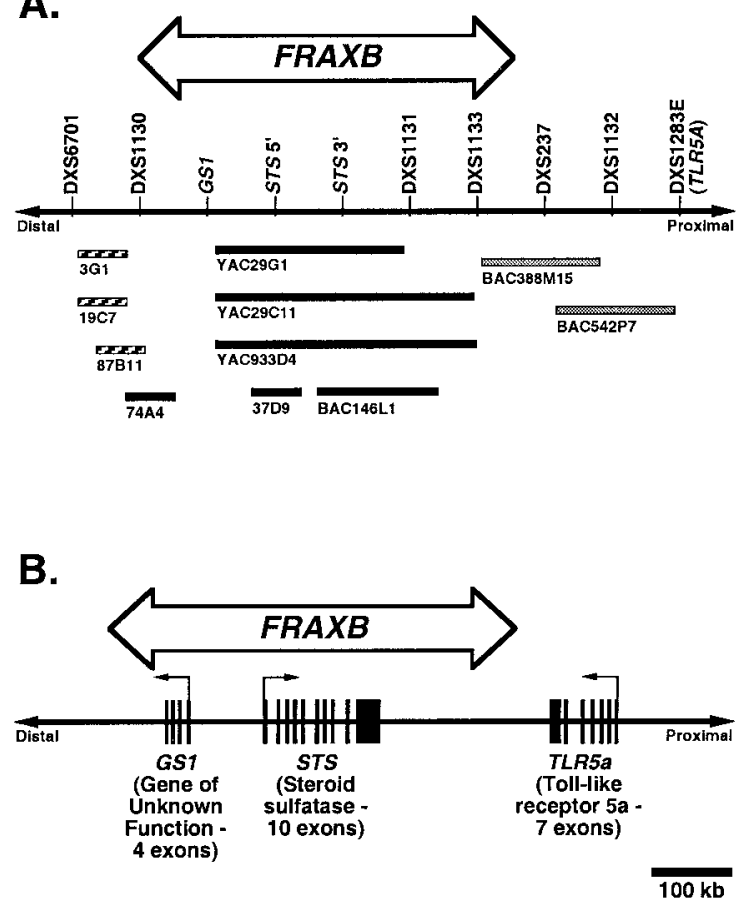

Figure I. Genomic organization of FRAXB at Xp22.3. A: Determination of extent of FRAXB by FISH analysis. Markers from Xp22.3 are arranged from distal (left) to proximal (right). The position of the fragile site is indicated at the top. Horizontal lines represent cosmid, BAC, and YAC clones used as FISH probes. Striped lines indicate clones that hybridized distal to the fragile site. Solid black lines indicate clones that hybridized across the fragile site break. Gray lines indicate clones that hybridized proximal to the fragile site. B: Positions of genes in the FRAXB region. The position of the fragile site is indicated at the top. GSI contains four exons near the distal boundary of FRAXB. STS contains 10 exons near the center of FRAXB. A third gene, TLR5a, contains seven exons positioned just proximal to FRAXB. Arrows indicate the direction of transcription.

very large fragile site, spanning approximately 500 $\mathrm{kb}$ of genomic sequence as defined by the location of gaps and breaks on metaphase chromosomes.

Approximately $235 \mathrm{~kb}$ of FRAXB have been sequenced from overlapping BACs GSHB-227L7 (GenBank accession no. AC005704) and RP11483M24 (GenBank accession no. AC073583). This sequence is composed of $57.7 \% \mathrm{~A}$ and $\mathrm{T}$. Much of the sequence contains repeat elements, including Alu (9.2\%), Mir (0.6\%), L1 (8.3\%), L2 (1.1\%), and long terminal repeat (LTR) (10.2\%) elements. The LTRs in this sequence include six human endogenous retrovirus-like (HERV-L)-derived sequences. In addition, the sequence contains simple di- and tetranucleotide repeats such as $(\mathrm{CA})_{\mathrm{n}}$, (TAGA) $)_{n}$, and (GGAA) $)_{n}$. Approximately $301 \mathrm{~kb}$ of sequence from overlapping BACs GSHB-214D18 (GenBank accession no. AC005296) and RP11143E20 (GenBank accession no. AC074034) is also available just proximal to FRAXB. BAC clone 
214D18 overlaps the BAC 542P7 used in our mapping studies. This adjacent sequence contains low to moderate amounts of Alu (4.5\%), Mir (1.9\%), L1 (7.5\%), and L2 (2.4\%) sequences. It is also characterized by a high proportion of LTRs (11.8\%), the majority of which are of retroviral origin, including two HERV-L-derived sequences.

\section{Identification of Genes in the FRAXB Region}

Several genes have been identified that map within FRAXB. A gene of unknown function, GS1, was identified in the distal third of FRAXB. It consists of four exons spanning approximately 105 $\mathrm{kb}$ with a predicted transcript of $2.1 \mathrm{~kb}$ (Yen et al., 1992). The microsomal steroid sulfatase (STS) gene had been previously cloned and mapped to Xp22.3 (Ballabio et al., 1987; Mohandas et al., 1987; Yen et al., 1987). The STS gene contains 10 exons spanning $146 \mathrm{~kb}$. Alternative polyadenylation signals in exon 10 generate transcripts of $2.7 \mathrm{~kb}, 5.2 \mathrm{~kb}$, and $7.0 \mathrm{~kb}$ in a tissue-specific manner (Yen et al., 1988). The STS gene is inactivated in X-linked icthyosis, primarily through large deletions. Both STS and GS1 were localized in a contig that maps to the FRAXB region (Lee et al., 1993). A third gene encoding the Toll-like receptor 5a (TLR5a) was identified at a $\mathrm{CpG}$ island just proximal to the fragile site (Lee et al., 1994). It contains seven exons spanning $28.6 \mathrm{~kb}$ that encode a $2.8 \mathrm{~kb}$ transcript. The positions of these genes relative to FRAXB are depicted in Figure 1B.

\section{Genes at FRAXB Are Inactivated in Cancer Cells}

As one measure of gene deletion and aberrant transcription, expression of the genes that colocalize with FRAXB (STS, GS1, TLR5a) was examined in a panel of 21 cancer cell lines and one normal fibroblast control by RT-PCR and subsequent Southern blot hybridization of products. Because of the high frequency of deletion at FRA3B, expression of the FHIT gene was examined as a positive control for loss of expression and production of aberrant transcripts. The Menkes disease gene $(A T P 7 A)$ at $\mathrm{Xq} 13$, which produces an RT-PCR product comparable in size to the FRAXB-associated genes, was used as a negative control.

STS was amplified using primers in exon 2 and in exon 10 upstream of the various polyadenylation signals to ensure that all of the possible transcripts could be detected. No aberrant transcripts were observed in any FRAXB-associated genes. However, these experiments revealed that $S T S$ and GS1 transcripts were absent in two cell lines, BIC-1 (esophageal) and SW-480 (colon). TLR5a was no
TABLE 2. Loss of Expression of Genes Associated With Fragile Sites

\begin{tabular}{lcccr}
\hline Gene & $\begin{array}{c}\text { Associated } \\
\text { fragile site }\end{array}$ & $\begin{array}{c}\text { Map } \\
\text { position }\end{array}$ & $\begin{array}{c}\text { Loss of } \\
\text { normal } \\
\text { transcript }\end{array}$ & \% Loss \\
\hline ATP7A & None & Xq13 & $0 / 21$ & 0.0 \\
FHIT & FRA3B & $3 p \mid 4$ & $9 / 21$ & 42.9 \\
GSI & FRAXB & Xp22 & $2 / 21$ & 9.5 \\
STS & FRAXB & Xp22 & $2 / 21$ & 9.5 \\
TLR5a & FRAXB & Xp22 & $1 / 21$ & 4.8 \\
Xp22 genes & FRAXB & Xp22 & $3 / 21$ & 14.3 \\
\hline
\end{tabular}

longer expressed in one cell line, 1315M02 (breast). Overall, $14.3 \%(3 / 21)$ of the cell lines had lost expression of one or more genes in the FRAXB region (Table 2). The BIC-1 cell line had previously been karyotyped and found to be disomic for the X chromosome (Fang et al., 2001). The 1315M02 breast cancer cell line was karyotyped and found to have the expected two copies of the $\mathrm{X}$ chromosome. SW-480 is a colon cancer cell line with a chromosome modal number of 55 derived from a male patient (Leibovitz et al., 1976).

No FHIT transcript was detected in $19.0 \%$ (4/21) of the cell lines. Five cell lines (23.8\%) had only aberrant FHIT transcript. An aberrant FHIT transcript in the presence of a normal FHIT transcript was seen in one cell line (4.8\%). In total, 10/21 $(47.6 \%)$ of the tumor cell lines were characterized by an alteration of FHIT expression.

An ATP7A PCR product of the expected size was seen in all cell lines examined. A summary of the gene expression data is shown in Table 3. Representative examples of RT-PCR data are shown in Figure 2A.

\section{Homozygous and Hemizygous Deletions at Common Fragile Sites}

The occurrence of homozygous or hemizygous deletions was examined in a panel of primary tumors and cancer cell lines to determine if sequences at common fragile sites are, in general, especially prone to deletions in cancer cells. Genomic PCR was performed on 21 cancer cell lines and six primary esophageal adenocarcinomas using markers from five common fragile sites: FRA3B (four markers), FRA7G (four markers), FRA7H (two markers), FRA16D (four markers), and FRAXB (six markers). Six markers from nonfragile site regions were also included as controls. These controls included two markers at $3 \mathrm{p} 14$, one marker at $7 \mathrm{q} 31$, one marker at Xp22.3, and two markers at $\mathrm{Xq} 13$. Whenever a marker failed to 
TABLE 3. Summary of Gene Expression and Homozygous Deletion Data

\begin{tabular}{|c|c|c|c|c|c|c|c|c|c|c|c|c|}
\hline \multirow[b]{2}{*}{ Cell line } & \multirow[b]{2}{*}{$\operatorname{Sex}^{\mathrm{a}}$} & \multirow[b]{2}{*}{ Type $^{\text {b }}$} & \multicolumn{5}{|c|}{ Gene expression ${ }^{c}$} & \multicolumn{5}{|c|}{ Homozygous deletion ${ }^{d}$} \\
\hline & & & FHIT & GSI & STS & $\operatorname{TLR} 5 \alpha$ & ATP7a & FRAXB & FRA3B & FRA7G & FRA7H & FRAI6D \\
\hline BIC-I & $M$ & Esophagus & $\bullet$ & $\bullet$ & $\bullet$ & + & + & $\bullet$ & $\bullet$ & + & + & $\bullet$ \\
\hline FLO-I & $M$ & Esophagus & $\bullet$ & + & + & + & + & + & + & + & + & $\bullet$ \\
\hline SEG-I & $M$ & Esophagus & + & + & + & + & + & + & $\bullet$ & + & + & + \\
\hline KATOIII & $M$ & Gastric & $\bullet$ & + & + & + & + & + & $\bullet$ & + & + & + \\
\hline HT-29 & $F$ & Colon & $\bullet$ & + & + & + & + & + & $\bullet$ & + & + & + \\
\hline SW480 & $M$ & Colon & + & $\bullet$ & $\bullet$ & + & + & $\bullet$ & $\bullet$ & + & + & + \\
\hline LSI80 & $F$ & Colon & + & + & + & + & + & + & + & + & + & + \\
\hline HeLa & $\mathrm{F}$ & Cervix & $\bullet$ & + & + & + & + & + & + & + & + & + \\
\hline SIHA & $F$ & Cervix & $\bullet$ & + & + & + & + & + & + & + & + & + \\
\hline CASKI & $\mathrm{F}$ & Cervix & + & + & + & + & + & + & + & + & + & + \\
\hline CC- 19 & $\mathrm{~F}$ & Cervix & $\bullet$ & + & + & + & + & + & $\bullet$ & + & + & + \\
\hline HCCI937 & $F$ & Breast & + & + & + & + & + & + & + & + & + & + \\
\hline SUMI49 & $\mathrm{F}$ & Breast & $\bullet$ & + & + & + & + & + & + & + & + & + \\
\hline SUMI59 & $F$ & Breast & + & + & + & + & + & + & + & + & + & + \\
\hline SUM44 & $\mathrm{F}$ & Breast & $\bullet$ & + & + & + & + & + & + & + & + & + \\
\hline SUMI02 & $F$ & Breast & + & + & + & + & + & + & + & + & + & + \\
\hline SUMI85 & $F$ & Breast & + & + & + & + & + & + & + & + & + & + \\
\hline SUMI90 & $\mathrm{F}$ & Breast & + & + & + & + & + & + & + & + & + & + \\
\hline SUM225 & $F$ & Breast & + & + & + & + & + & + & + & + & + & + \\
\hline SUM229 & $F$ & Breast & + & + & + & + & + & + & + & + & + & + \\
\hline SUMI5I3M02 & $\mathrm{F}$ & Breast & + & + & + & $\bullet$ & + & + & + & + & + & + \\
\hline$M 60^{e}$ & $M$ & Esophagus & ND & ND & ND & ND & ND & + & + & + & + & + \\
\hline $\mathrm{P} / 6^{\mathrm{e}}$ & $M$ & Esophagus & ND & ND & ND & ND & ND & + & + & + & + & + \\
\hline F93 & $M$ & Esophagus & ND & ND & ND & ND & ND & + & + & + & + & + \\
\hline$S 45^{e}$ & $M$ & Esophagus & ND & ND & ND & ND & ND & $\bullet$ & + & $\bullet$ & $\bullet$ & $\bullet$ \\
\hline $\mathrm{DO} \mathrm{I}^{\mathrm{e}}$ & $M$ & Esophagus & ND & ND & ND & ND & ND & + & + & + & + & + \\
\hline $\mathrm{L}^{8} 6^{\mathrm{e}}$ & $M$ & Esophagus & ND & ND & ND & ND & ND & $\bullet$ & + & + & + & + \\
\hline
\end{tabular}

aM, male; F, female.

bTumor origin.

'Gene expression determined by RT-PCR. “+” indicates normal expression, "•” indicates loss of normal transcript, "ND” indicates no data due to unavailable RNA from primary tumors.

"Homozygous deletion determined by genomic PCR. "+" indicates no deletion, "•" indicates homozygous deletion.

ePrimary tumor.

amplify through two separate rounds of PCR, multiplex PCR was performed with a second marker to confirm the reliability of the DNA, PCR reagents, and conditions. Representative examples of multiplex PCR showing deletions are illustrated in Figure 2B.

Every fragile site was characterized by homozygous deletion in at least one tumor or cell line. The most frequent deletions were observed at markers from FRA3B, with 6/27 (22.2\%) samples demonstrating homozygous deletions in at least one marker in this fragile site. FRAXB was characterized by deletions in 4/27 (14.8\%) of samples. FRA16D was homozygously deleted in $3 / 27(11.1 \%)$ specimens. FRA7G and FRA7H were each homozygously deleted in $1 / 27(3.7 \%)$ of the samples (Tables 3, 4). None of the samples had homozygous deletions at any of the control markers or at loci flanking FRA3B and FRAXB. Overall, 33.3\% (9/27) of the tumors and cell lines were characterized by homozygous dele- tions of sequences from at least one fragile site. Three of the specimens (11.1\%) had deletions at more than one fragile site. One cell line, BIC-1, had homozygous deletions at FRA3B, FRA16D, and FRAXB. A second cell line, SW-480, had deletions at FRA3B and FRAXB. One of the primary esophageal adenocarcinomas, S45, had deletions at FRA7G, FRA7H, FRA16D, and FRAXB. Two of the deletions at FRAXB occurred in cell lines that were included in the gene expression analyses, BIC-1 and SW-480. In both cases, deletion of FRAXB sequences correlated with loss of expression of STS and GS1. A summary of the homozygous deletion data is shown in Table 3.

\section{Deletion Breakpoints Colocalize With Fragile-Site Boundaries}

In several cases, deletion breakpoints colocalized with the established boundaries of the fragile sites. As mentioned previously, the distal boundary of FRAXB is at DXS1130 and the proximal boundary 


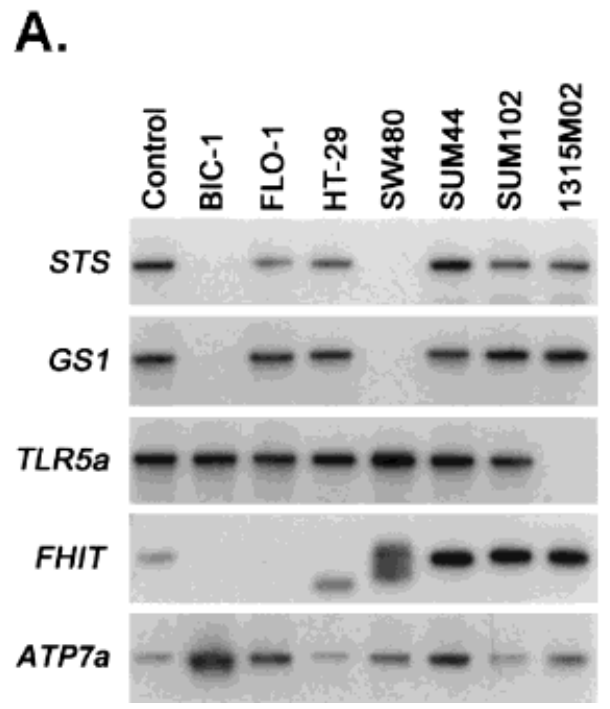

Figure 2. Homozygous deletions and loss of gene expression at common fragile sites in cancer cells. A: Examples of loss of gene expression at FRAXB detected by RT-PCR. A control fibroblast and seven cancer cell lines are indicated above each lane. The RT-PCR products corresponding to STS, GSI, and TLR5 $a$ are shown in the first three panels, respectively. The fourth panel shows RT-PCR results for FHIT, containing both loss of gene product and aberrant transcripts. The

is between DXS1133 and DXS237. During the course of the homozygous deletion studies, we discovered that two tumor cell lines, BIC-1 and SW480, appear to have deletions of approximately the same size at FRAXB. PCR with additional markers revealed that these two cell lines indeed shared similar deletion breakpoints. Furthermore, these breakpoints colocalize with the boundaries of the FRAXB fragile site, as determined by our FISH studies (Fig. 3). Both cell lines have deletions at DXS1130 but retain the next most distal marker tested, DXS6701, indicating that the distal deletion breakpoint is between these two markers. Similarly, both cell lines have deletions at DXS1133 but retain the next most proximal marker, DXS237. These data indicate that the proximal deletion breakpoint is between these two markers in these cell lines. These deletions appear to remove sequences necessary for expression of FRAXB. When BIC-1 cells were treated with aphidicolin to induce fragile sites, no gaps or breaks were observed at FRAXB in 100 metaphase cells, indicating that the deletion eliminated the site's fragility.

Further analyses with the two primary esophageal adenocarcinomas characterized by FRAXB deletions revealed that they share the same proximal deletion boundary between DXS1133 and DXS237. The proximal breakpoint of tumor L86 is between DXS1133 and DXS1131, within the frag-

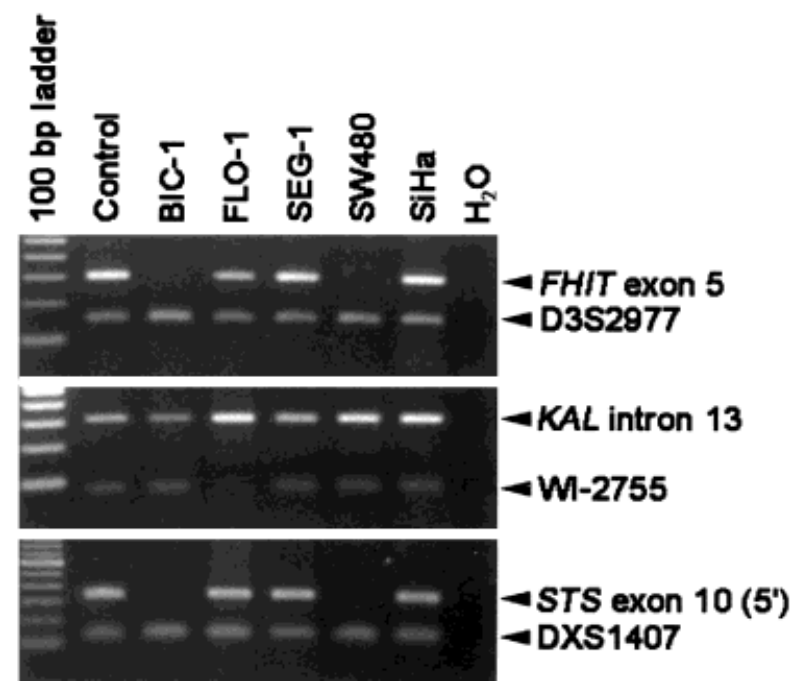

fifth panel contains products from ATP7A, a control. B: Examples of homozygous deletions at common fragile sites detected by multiplex PCR. A control fibroblast and seven cancer cell lines are indicated above each lane. Representative PCR results revealing homozygous deletions are shown for FHIT exon 5 (FRA3B), WI-2755 (FRAI6D), and STS exon 10 (FRAXB).

TABLE 4. Homozygous Deletions at Common Fragile Sites

\begin{tabular}{|c|c|c|c|}
\hline $\begin{array}{l}\text { Fragile } \\
\text { site }\end{array}$ & Marker & $\begin{array}{c}\text { Homozygous } \\
\text { deletions }\end{array}$ & $\begin{array}{l}\text { Total } \\
\text { deletions } \\
\text { in region }\end{array}$ \\
\hline \multirow[t]{4}{*}{ FRA3B } & D3S2977 & $0 / 27(0.0 \%)$ & \\
\hline & D3S4I03 & $3 / 27$ (II.1\%) & $6 / 27(22.2 \%)$ \\
\hline & FHIT exon 5 & $3 / 27$ (11.1\%) & \\
\hline & D3SI48I & $2 / 27(7.4 \%)$ & \\
\hline \multirow[t]{3}{*}{ FRA7G } & D7S486 & $0 / 27(0.0 \%)$ & \\
\hline & $7 G 2$ & $\mathrm{I} / 27(3.7 \%)$ & $\mathrm{I} / 27(3.7 \%)$ \\
\hline & $7 \mathrm{G} / 4$ & $\mathrm{I} / 27(3.7 \%)$ & \\
\hline \multirow[t]{2}{*}{ FRA7H } & WI-I6323 & $\mathrm{I} / 27(3.7 \%)$ & $\mathrm{I} / 27(3.7 \%)$ \\
\hline & D7S649 & $0 / 27(0.0 \%)$ & \\
\hline \multirow{4}{*}{ FRAI6D } & DI6S5I8 & $\mathrm{I} / 27(3.7 \%)$ & \\
\hline & WI-2755 & $2 / 27(7.4 \%)$ & $3 / 27$ (1I.1\%) \\
\hline & AA398024 & $2 / 27(7.4 \%)$ & \\
\hline & DI6S3029 & $1 / 27(3.7 \%)$ & \\
\hline \multirow{6}{*}{ FRAXB* } & DXS670I & $\mathrm{I} / 27(3.7 \%)$ & \\
\hline & DXSII30 & $3 / 27$ (II.1\%) & \\
\hline & STS exon 2 & $3 / 27(11.1 \%)$ & $4 / 27(14.8 \%)$ \\
\hline & STS exon 10 & $3 / 27$ (II.1\%) & \\
\hline & DXSII33 & 4/27 (I4.8\%) & \\
\hline & DXSI407 & $0 / 27(0.0 \%)$ & \\
\hline \multirow{6}{*}{ Controls } & D7S500 (7q3I) & $0 / 27(0.0 \%)$ & \\
\hline & KAL intron $13\left(X_{p} 22.3\right)$ & $0 / 27(0.0 \%)$ & \\
\hline & DXS8079 (Xq13) & $0 / 27(0.0 \%)$ & $0 / 27(0.0 \%)$ \\
\hline & ATP7A $(\mathrm{Xql} 3)$ & $0 / 27(0.0 \%)$ & \\
\hline & D3S3577 (3p|4) & $0 / 27(0.0 \%)$ & \\
\hline & D3S4483 (3p|4.2) & $0 / 27(0.0 \%)$ & \\
\hline
\end{tabular}

*Homozygous deletions or hemizygous deletions in cell lines or tumors with one $\mathrm{X}$ chromosome. 


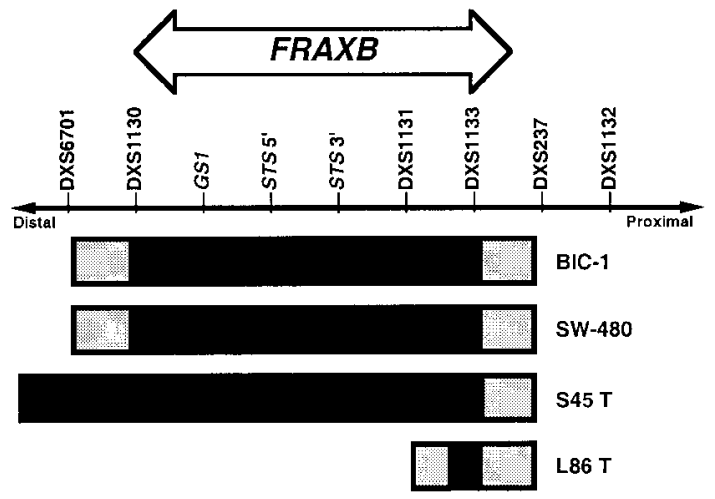

Figure 3. Colocalization of FRAXB boundaries and deletion breakpoints in cancer cells. Markers from Xp22.3 are arranged from distal (left) to proximal (right) with the position of FRAXB indicated at the top. Deleted regions in two cancer cell lines (BIC-I and SW-480) and two primary esophageal adenocarcinomas (S45 T and L86 T) are indicated with black bars underneath the deleted markers. Shaded areas indicate the regions where the deletion breaks occur.

ile site, whereas tumor S45 appears to have a terminal deletion.

\section{DISCUSSION}

\section{Structure and Composition of FRAXB}

We have defined the boundaries of the common fragile site FRAXB at Xp22.3, localizing this fragile site to approximately $500 \mathrm{~kb}$ between DXS1130 and DXS237. The FRAXB region contains three previously identified genes, STS, GS1, and TLR5a. This region is currently being sequenced by the Human Genome Sequencing Center at the Baylor College of Medicine, and about $235 \mathrm{~kb}$ of sequence data are available from within FRAXB (GenBank Accession nos. AC005704 and AC073583). Additional sequence is available flanking the fragile site boundaries. From the available data, FRAXB appears to be moderately A-T rich $(57.7 \%)$ and consists of approximately $31 \%$ interspersed repeat elements. This repeat element content is slightly lower than the $38.5 \%$ expected for DNA of this A-T content (Smit et al., 1996). Sequence analysis revealed that about $301 \mathrm{~kb}$ of sequence immediately proximal to FRAXB had a slightly higher A-T content $(61 \%)$ and a similar frequency of interspersed repeats $(32 \%)$. The proportions of long terminal repeats, transposable elements, L2s, and Mirs in the FRAXB sequence are similar to those previously reported for FRA3B, FRA7H, and FRA16D (Ried et al., 2000). There are differences in the proportion of Alu and L1 elements seen in FRAXB and other fragile sites. FRA3B and FRA7H have a relatively high proportion of L1 sequences, $11.7 \%$ and $13.2 \%$, respectively (Ried et al., 2000). The FRAXB sequence contains a slightly lower proportion of L1 sequences $(8.3 \%)$. FRA3B also has a fairly low Alu content of $6.3 \%$. The available sequence from FRAXB has a moderate Alu content of approximately $9.2 \%$. FRA16D sequence contains $2.8 \% \mathrm{~L} 1$ and $13.8 \%$ Alu (Ried et al., 2000). In these respects, from the sequence currently available, FRAXB appears to fall between FRA3B and FRA16D in terms of repeat content. It is noteworthy that the sequence immediately proximal to FRAXB has a lower Alu content of $4.5 \%$ and an L1 content of $7.5 \%$.

Viral integration sites have been previously reported at several common fragile sites. FRA3B is associated with an HPV16 integration site that was described in a primary cervical carcinoma (Wilke et al., 1996). More recently, an endogenous HERV-H sequence was identified at FRA7G (Huang et al., 1998) and an SV40 integration site was found in FRA7H (Mishmar et al., 1998). Our finding that sequences from within FRAXB and just proximal to the FRAXB proximal boundary as defined here contain a high proportion of retroviral sequences, including multiple HERV-L sequences, appears to support the hypothesis that common fragile sites are preferential sites of viral integration. Additional sequence from within the fragile site is needed to confirm this suggestion.

\section{Deletions and Loss of Gene Expression at Common Fragile Sites}

Previous studies investigating fragile site stability have shown frequent deletions at FRA3B in a variety of cancers and cancer cell lines, including lung, digestive tract, and breast cancer (Negrini et al., 1996; Ohta et al., 1996; Sozzi et al., 1996; Druck et al., 1997; Michael et al., 1997). Recently, homozygous deletions have been observed in tumors at other fragile sites as well, including FRA7G in ovarian cancer and FRA16D in gastric adenocarcinoma and multiple myeloma, suggesting that common fragile sites are generally unstable and may lead to gene inactivation in cancer cells (Huang et al., 1999; Mangelsdorf et al., 2000). In addition, translocations within fragile sites have been identified at FRA3B and FRA16D (Ried et al., 2000; Fang et al., 2001). All of these alterations occur in regions that have been previously implicated in tumorigenesis, suggesting that increased genomic instability during tumor development may lead to preferential inactivation of genes at fragile sites and a selective growth advantage when the inactivated genes have tumor suppressor activity. FRAXB is not associated with any known tumor suppressor 
activity, based on LOH studies and locations of known tumor suppressor genes. In addition, $85 \%$ of $\mathrm{X}$-linked ichthyosis cases are due to inactivation of STS through large deletions at $\mathrm{Xp} 22$ that include FRAXB and large amounts of flanking sequence (Ballabio et al., 1987; Gillard et al., 1987; Yen et al., 1987). Patients with X-linked ichthyosis are not characterized by tumor development, providing further support that $\mathrm{Xp} 22.3$ is devoid of tumor suppressor activity. While we cannot completely rule out the possibility that an unknown tumor suppressor gene may map to this region, or that a selective advantage is conferred to cancer cells with $\mathrm{Xp} 22.3$ deletions, it is likely that fragile site instability at FRAXB in cancer cells can be examined without selection for deletion events.

As expected, a high frequency of deletions was observed at FRA3B in our panel of cancer cell lines and primary tumors. FRA3B is the most highly expressed common fragile site under a variety of conditions (Glover, 1998). Deletions were also seen, at a somewhat lower frequency, at FRA7G, FRA7H, FRA16D, and FRAXB. The relative frequency of deletions at these fragile sites correlates with the frequency at which these fragile sites are generally expressed on metaphase chromosomes (Glover et al., 1984). Homozygous deletions were primarily seen in cells derived from esophageal and colon tumors, with deletions rarely observed in cervical cancer cell lines and never observed in breast cancer lines. The fact that none of the nonfragile site control markers and few of the sequences immediately flanking the fragile sites were deleted suggests that these deletions are specific to the fragile sites, and not simply the result of a generalized genomic instability resulting in random deletions. This hypothesis is also supported by the three samples that were characterized by homozygous deletions at multiple fragile sites. It should be noted that additional small interstitial deletions might have occurred in the fragile site in the regions between the markers examined, as has been found at FRA3B in various tumors and tumor cell lines. As such, the deletion frequencies reported here are likely an underestimate of the actual deletions occurring within fragile sites.

Aberrant FHIT transcripts, indicating deletions and aberrant splicing, have been identified by RTPCR in numerous cancers, including lung, digestive tract, and breast cancer (Negrini et al., 1996; Ohta et al., 1996; Sozzi et al., 1996; Druck et al., 1997; Michael et al., 1997). For example, our group performed studies to investigate deletions in FHIT in primary esophageal tumors and the relationship of FHIT deletions to FRA3B. We concluded from these studies that both aberrant splicing and genomic deletions of FHIT are indeed frequently seen in primary tumors and occur at an early stage, consistent with a role for FHIT as a tumor suppressor gene (Michael et al., 1997). We and others have hypothesized that FHIT inactivation occurs as a consequence of fragile site instability during tumorigenesis. One result of the deletions at FRAXB in our cell lines is the loss of expression of associated genes, GS1 and STS. It is of note that, whereas aberrant transcripts were frequently seen in FHIT, they were never observed at any of the genes at FRAXB. This is likely due to the sizes of these genes and their positions relative to the fragile sites. FHIT is a very large gene, spanning approximately $1,000 \mathrm{~kb}$ of genomic DNA. FRA3B is completely contained within the gene, centered around exon 5. Deletions at this fragile site can eliminate exon 5 and surrounding sequences without abolishing expression of the gene, resulting in aberrant transcripts. Aberrant transcripts could also arise during RNA processing of this large and complex region. In contrast, the genes at FRAXB are relatively small and are completely contained within the fragile site boundaries. As a result, deletions at FRAXB are likely completely to eliminate GS1 and/or STS expression rather than cause aberrant transcripts. These data support the hypothesis that common fragile site instability in cancer cells results in a loss of associated gene function due to deletion events. If genes associated with specific fragile sites, such as FHIT at FRA3B, have important tumor suppressor functions, this generalized fragile site instability can confer a growth advantage on cells that have undergone fragile site deletions. In the case of FRAXB, no known tumor suppressor activity has been associated with the region. Thus, a growth advantage conferred by deletions in FRAXB is not known, but cannot be ruled out completely.

\section{Colocalization of Fragile Site and Deletion Boundaries in Cancer Cells}

Of the four samples that had homozygous deletions at FRAXB, two had deletion breakpoints corresponding to the fragile site boundaries and the other two had proximal deletion breakpoints at the proximal boundary of FRAXB (Fig. 3). These coincident deletion/fragile site boundaries provide further evidence for the preferential instability of common fragile sites in cancer. The deletion breakpoints seen in the BIC-1 esophageal cancer cell line also provide insight into the mechanism of 
FRAXB fragility. The fragile site region appears to be precisely deleted in this cell line, with little or no flanking DNA deleted. This cell line no longer displays fragility at $\mathrm{Xp} 22.3$, indicating that sequence is important for fragility, and that this necessary sequence is found within the fragile site, rather than being located proximal or distal to the fragile site.

While the FRAXB region has not previously been shown to be deleted in cancers, deletions in another type of disorder have been reported. The involvement of STS in X-linked icthyosis is unusual in that it is primarily inactivated through large genomic deletions, rather than by point mutations or small deletions (Yen et al., 1987). These deletions are thought to arise through unequal meiotic recombination events between a family of genes known as VCX (variably charged, $\mathrm{X}$-chromosome mRNA on CRI-232) on Xp that is highly conserved (Knowlton et al., 1989; Yen et al., 1990; Fukami et al., 2000; Lahn et al., 2000). It is unlikely that the conserved FRAXB deletions observed in our primary tumors and cancer cell lines are due to somatic recombination between members of this family. Several published reports describe deletions in $\mathrm{X}$-linked icthyosis caused by $V C X$ recombination. The deletions attributed to these recombination events have breakpoints distal to DXS6701 and proximal to DXS237, two markers retained in our specimens (Yen et al., 1990; Fukami et al., 2000). In addition, none of the VCX genes mapped to Xp22.3 are localized within FRAXB.

In summary, we have localized and defined the boundaries and genes associated with the common fragile site FRAXB. This fragile site spans approximately $500 \mathrm{~kb}$ of A-T-rich DNA. The repeat element content determined by analysis of available sequence reveals that FRAXB more closely resembles FRA16D than either FRA3B or FRA7H. We have mapped three known genes to the FRAXB region, STS, GS1, and TLR5a. We have examined FRAXB and four other fragile sites for instability at both the DNA and RNA levels as a test of the hypothesis that common fragile sites are generally unstable in cancer cells. Our results are consistent with the conclusion that common fragile sites, as a class, are unstable in cancer cells, resulting in deletions and loss of associated gene expression.

\section{ACKNOWLEDGMENTS}

We thank David Nelson at Baylor University for providing us with genomic clones and some sequences used in these experiments. The work was supported by National Cancer Institute grant
CA43222 (T.W.G.) and the University of Michigan Comprehensive Cancer Center Pardee Fellowship (M.F.A.).

\section{REFERENCES}

Ballabio A, Parenti G, Carrozzo R, Sebastio G, Andria G, Buckle V, Fraser N, Craig I, Rocchi M, Romeo G. 1987. Isolation and characterization of a steroid sulfatase cDNA clone: genomic deletions in patients with $\mathrm{X}$-chromosome-linked ichthyosis. Proc Natl Acad Sci USA 84:4519-4523.

Barnes LD, Garrison PN, Siprashvili Z, Guranowski A, Robinson AK, Ingram SW, Croce CM, Ohta M, Huebner K. 1996. FHIT, a putative tumor suppressor in humans, is a dinucleoside $5^{\prime}, 5^{\prime \prime \prime}$ P1,P3-triphosphate hydrolase. Biochemistry 35:11529-11535.

Coquelle A, Pipiras E, Toledo F, Buttin G, Debatisse M. 1997. Expression of fragile sites triggers intrachromosomal mammalian gene amplification and sets boundaries to early amplicons. Cell 89:215-225.

Dagenais SL, Guevara-Fujita M, Loechel R, Burgess AC, Miller DE, Yuzbasiyan-Gurkan V, Brewer GJ, Glover TW. 1999. The canine copper toxicosis locus is not syntenic with $A T P 7 B$ or ATX1 and maps to a region showing homology to human 2p21. Mamm Genome 10:753-756.

Druck T, Hadaczek P, Fu TB, Ohta M, Siprashvili Z, Baffa R, Negrini M, Kastury K, Veronese ML, Rosen D, Rothstein J, McCue P, Cotticelli MG, Inoue H, Croce CM, Huebner K. 1997. Structure and expression of the human FHIT gene in normal and tumor cells. Cancer Res 57:504-512.

Dumon KR, Ishii H, Fong LY, Zanesi N, Fidanza V, Mancini R,Vecchione A, Baffa R, Trapasso F, During MJ, Huebner K, Croce CM. 2001. FHIT gene therapy prevents tumor development in Fhit-deficient mice. Proc Natl Acad Sci USA 98:33463351.

Fang JM, Arlt MF, Burgess AC, Dagenais SL, Beer DG, Glover TW. 2001. Translocation breakpoints in FHIT and FRA3B in both homologs of chromosome 3 in an esophageal adenocarcinoma. Genes Chromosomes Cancer 30:292-298.

Fong LY, Fidanza V, Zanesi N, Lock LF, Siracusa LD, Mancini R, Siprashvili Z, Ottey M, Martin SE, Druck T, McCue PA, Croce CM, Huebner K. 2000. Muir-Torre-like syndrome in FHIT-deficient mice. Proc Natl Acad Sci USA 97:4742-4747.

Fukami M, Kirsch S, Schiller S, Richter A, Benes V, Franco B, Muroya K, Rao E, Merker S, Niesler B, Ballabio A, Ansorge W, Ogata T, Rappold GA. 2000. A member of a gene family on $\mathrm{Xp22.3,} \mathrm{VCX-A,} \mathrm{is} \mathrm{deleted} \mathrm{in} \mathrm{patients} \mathrm{with} \mathrm{X-linked} \mathrm{nonspecific}$ mental retardation. Am J Hum Genet 67:563-573.

Geurts JM, Schoenmakers EF, Roijer E, Stenman G, Van de Ven WJ. 1997. Expression of reciprocal hybrid transcripts of HMGIC and FHIT in a pleomorphic adenoma of the parotid gland. Cancer Res 57:13-17.

Gillard EF, Affara NA, Yates JRW, Goudie DR, Lambert J, Aitken DA, Ferguson-Smith MA. 1987. Deletion of a DNA sequence in eight of nine families with $\mathrm{X}$-linked ichthyoisis (steroid sulphatase deficiency). Nucleic Acids Res 15:3977-3985.

Glover TW. 1998. Instability at chromosomal fragile sites. Recent Results Cancer Res 154:185-199.

Glover TW, Berger C, Coyle J, Echo B. 1984. DNA polymerase a inhibition by aphidicolin induces gaps and breaks at common fragile sites in human chromosomes. Hum Genet 67:136-142.

Glover TW, Coyle-Morris JF, Li FP, Brown RS, Berger CS. 1988. Translocation $\mathrm{t}(3 ; 8)(\mathrm{p} 14.2 ; \mathrm{q} 24.1)$ in renal cell carcinoma affects expression of the common fragile site at 3p14 (FRA3B) in lymphocytes. Cancer Genet Cytogenet 31:69-73.

Hibi K, Takahashi T, Yamakawa K, Ueda R, Sekido Y, Ariyoshi Y, Suyama M, Takagi H, Nakamura Y, Takahashi T. 1992. Three distinct regions involved in $3 \mathrm{p}$ deletion in human lung cancer. Oncogene 7:445-449.

Huang H, Qian J, Proffit J, Wilber K, Jenkins R, Smith DI. 1998. FRA7G extends over a broad region: coincidence of human endogenous retroviral sequences (HERV-H) and small polydispersed circular DNAs (spcDNA) and fragile sites. Oncogene 16: 2311-2319.

Huang H, Reed CP, Mordi A, Lomberk G, Wang L, Shridhar V, Hartmann L, Jenkins R, Smith DI. 1999. Frequent deletions within FRA7G at 7q31.2 in invasive epithelial ovarian cancer. Genes Chromosomes Cancer 24:48-55.

Huebner K, Hadaczek P, Siprashvili Z, Druck T, Croce CM. 1997. The FHIT gene, a multiple tumor suppressor gene encompassing 
the carcinogen sensitive chromosome fragile site, FRA3B. Biochim Biophys Acta 1332:M65-70.

Knowlton RG, Nelson CA, Brown VA, Page DC, Donis-Keller H. 1989. An extremely polymorphic locus on the short arm of the human $\mathrm{X}$ chromosome with homology to the long arm of the $\mathrm{Y}$ chromosome. Nucleic Acids Res 17:423-437.

Lahn BT, Page DC. 2000. A human sex-chromosomal gene family expressed in male germ cells and encoding variably charged proteins. Hum Mol Genet 9:311-319.

Lee WC, Ferrero GB, Chinault AC, Yen PH, Ballabio A. 1993. A yeast artificial chromosome contig linking the steroid sulfatase and Kallmann syndrome loci on the human X chromosome short arm. Genomics18:1-6.

Lee WC, Salido E, Yen PH. 1994. Isolation of a new gene GS2 $(D X S 1283 E)$ from a $\mathrm{CpG}$ island between STS and KAL1 on Xp22.3. Genomics 22:372-376.

Leibovitz A, Stinson JC, McCombs WB III, McCoy CE, Mazur KC, Mabry ND. 1976. Classification of human colorectal adenocarcinoma cell lines. Cancer Res 36:4562-4569.

Mangelsdorf M, Ried K, Woollatt E, Dayan S, Eyre H, Finnis M, Hobson L, Nancarrow J, Venter D, Baker E, Richards RI. 2000. Chromosomal fragile site FRA16D and DNA instability in cancer. Cancer Res 60:1683-1689.

Michael D, Beer DG, Wilke CW, Miller DE, Glover TW. 1997. Frequent deletions of FHIT and FRA3B in Barrett's metaplasia and esophageal adenocarcinomas. Oncogene 15:1653-1659.

Mishmar D, Rahat A, Scherer SW, Nyakatura G, Hinzmann B, Kohwi Y, Mandel-Gutfroind Y, Lee JR, Drescher B, Sas DE, Margalit H, Platzer M, Weiss A, Tsui LC, Rosenthal A, Kerem B. 1998. Molecular characterization of a common fragile site (FRA7H) on human chromosome 7 by the cloning of a simian virus 40 integration site. Proc Natl Acad Sci USA 95:8141-8146.

Mohandas T, Geller RL, Yen PH, Rosendorff J, Bernstein R, Yoshida A, Shapiro LJ. 1987. Cytogenetic and molecular studies on a recombinant human $\mathrm{X}$ chromosome: implications for the spreading of $\mathrm{X}$ chromosome inactivation. Proc Natl Acad Sci USA 84: 4954-4958.

Negrini M, Monaco C, Vorechovsky I, Ohta M, Druck T, Baffa R, Huebner K, Croce CM. 1996. The FHIT gene at 3p14.2 is abnormal in breast carcinomas. Cancer Res 56:3173-3179.

Ohta M, Inoue H, Cotticelli MG, Kastury K, Baffa R, Palazzo J, Siprashvili Z, Mori M, McCue P, Druck T. 1996. The FHIT gene, spanning the chromosome 3 p14.2 fragile site and renal carcinomaassociated $\mathrm{t}(3 ; 8)$ breakpoint, is abnormal in digestive tract cancers. Cell 84:587-597.

Otterson GA, Xiao GH, Geradts J, Jin F, Chen W, Niklinska W, Kaye FJ, Yeung RS. 1998. Protein expression and functional analysis of the FHIT gene in human tumor cells. J Natl Cancer Inst 90:426-432.

Ried K, Finnis M, Hobson L, Mangelsdorf M, Dayan S, Nancarrow JK, Woollatt E, Kremmidiotis G, Gardner A, Venter D, Baker E, Richards RI. 2000. Common chromosomal fragile site FRA16D sequence: identification of the FOR gene spanning FRA16D and homozygous deletions and translocation breakpoints in cancer cells. Hum Mol Genet 9:1651-1663.

Sambrook J, Fritsch EF, Maniatis T. 1989. Molecular Cloning. A Laboratory Manual. Plainview, NY: Cold Spring Harbor Laboratory Press.

Siprashvili Z, Sozzi G, Barnes LD, McCue P, Robinson AK, Eryomin V, Sard L, Tagliabue E, Greco A, Fusetti L, Schwartz G, Pierotti MA, Croce CM, Huebner K. 1997. Replacement of FHIT in cancer cells suppresses tumorigenicity. Proc Natl Acad Sci USA 94:13771-13776.

Smit A. 1996. The origin of interspersed repeats in the human genome. Curr Opin Genet Dev 6:743-748.

Sozzi G, Veronese ML, Negrini M, Baffa R, Cotticelli MG, Inoue H, Tornielli S, Pilotti S, De Gregorio L, Pastorino U, Pierotti MA, Ohta M, Huebner K, Croce CM. 1996. The FHIT gene 3p14.2 is abnormal in lung cancer. Cell 85:17-26.

Wilke CM, Hall BK, Hoge A, Paradee W, Smith DI, Glover TW. 1996. FRA3B extends over a broad region and contains a spontaneous HPV16 integration site: direct evidence for the coincidence of viral integration sites and fragile sites. Hum Mol Genet 5:187195.

Wu R, Connolly DC, Dunn RL, Cho KR. 2000. Restored expression of fragile histidine triad protein and tumorigenicity of cervical carcinoma cells. J Natl Cancer Inst 92:338-344.

Yen PH, Allen E, Marsh B, Mohandes T, Wang N, Taggart RT, Shapiro LJ. 1987. Cloning and expression of steroid sulfatase cDNA and the frequent occurrence of deletions in STS deficiency: implications for X-Y interchange. Cell 49:443-454.

Yen PH, Marsh B, Allen E, Tsai SP, Ellison J, Connolly L, Neiswanger K, Shapiro LJ. 1988. The human X-linked steroid sulfatase gene and a Y-encoded pseudogene: evidence for an inversion of the $\mathrm{Y}$ chromosome during primate evolution. Cell $55: 1123-1135$

Yen PH, Li XM, Tsai SP, Johnson C, Mohandas T, Shapiro LJ. 1990. Frequent deletions of the human X chromosome distal short arm result from recombination between low copy repetitive elements. Cell 61:603-610.

Yen PH, Ellison J, Salido EC, Mohandas T, Shapiro L. 1992. Isolation of a new gene from the distal short arm of the human $\mathrm{X}$ chromosome that escapes X-inactivation. Hum Mol Genet 1:4752 . 